\title{
A contribuição do acolhimento e do vínculo na humanização da prática do cirurgião-dentista no Programa Saúde da Família
}

Poliana Miranda Pinheiro ${ }^{1}$

Lúcia Conde de Oliveira²

PINHEIRO, P.M.; OLIVEIRA, L.C. The contribution of receptivity and bonding towards humanization of dental surgeons' practice within the Family Health Program. Interface - Comunic., Saude, Educ., v.15, n.36, p.187-98, jan./mar. 2011.

This study aimed to ascertain how the soft technologies of receptivity and bonding are used in dentists' practice within the Family Health Program in the municipality of Fortaleza, Ceará, towards constructing humanized care. This was a qualitative investigation conducted among 16 dental surgeons using semistructured interviews and simple observation to gather data. The data were evaluated using content analysis. The results showed that the dentists were making greater use of these technologies in their practice, but receptivity was identified more as a first stage in organizing the demand than as an attitude of listening. The latter stance was more associated with bonding. The great demand has contributed towards tension lines between dentists and users and has forced dental practitioners towards practices that are still tied to the office. New spaces would be important for using these technologies, given that these look beyond the disease, to the individual.

Keywords: Receptivity. Bonding. Humanization. Dental surgeon.
Objetiva-se compreender como são empregadas as tecnologias leves do acolhimento e vínculo na prática do dentista, no Programa Saúde da Família do município de Fortaleza, Ceará, no sentido da construção do cuidado humanizado. Trata-se de pesquisa qualitativa realizada com 16 cirurgiõesdentistas, utilizando-se, para coleta de dados, entrevista semiestruturada e observação simples e, para análise dos dados, a análise de conteúdo. Os resultados mostram o dentista fazendo maior uso dessas tecnologias em sua prática, porém o acolhimento é mais identificado como primeira etapa de organização da demanda do que como atitude de escuta, postura esta mais associada ao vínculo. A grande demanda tem contribuído com linhas de tensão entre dentista e usuário e forçado o odontólogo a uma prática ainda presa ao consultório. Novos espaços seriam importantes na utilização dessas tecnologias, já que estas consideram, para além da doença, o indivíduo.

Palavras-chave: Acolhimento. Vínculo. Humanização. Cirurgião-dentista.
${ }^{1}$ Curso de Odontologia, Departamento de Clínica Odontológica,

Universidade Federal do Ceará. Avenida Filomeno Gomes, 733, apto. 601. Jacarecanga, Fortaleza, CE, Brasil. 60.010-281. polipmp@gmail.com 2 Universidade Estadual do Ceará. 


\section{Introdução}

A conquista do Sistema Único de Saúde (SUS) tem nos desafiado a desenvolver modelos explicativos para compreendermos esse sistema e suas práticas, bem como elaborarmos propostas de intervenção que favoreçam o aperfeiçoamento do mesmo. Teixeira (2003) declara que os debates teóricos e políticos concentraram-se nas questões jurídico-legais e político-institucionais, especialmente voltados para a gestão e o financiamento, e que a temática do processo de trabalho passou por um período de pouco evidência. Contudo, a constatação de que não avançamos muito na mudança do modelo assistencial tem trazido, para o centro das discussões acadêmicas e no espaço dos serviços de saúde, o processo de trabalho em saúde.

Em 1994, foi lançado, pelo Ministério da Saúde (MS), o Programa Saúde da Família (PSF) como estratégia de um novo modelo assistencial que busca uma visão mais integral do sujeito e ações que envolvam a comunidade onde este se encontra. O PSF parte de uma nova forma de se pensar o processo saúde-doença e o processo de trabalho em saúde, compreendendo o ser humano não só na sua dimensão biológica, mas também as influências psicológicas, sociais e culturais que marcam o meio onde o sujeito está inserido. Esta estratégia destina-se, entre outras coisas, a: oferecer um cuidado integral, intervir nos fatores de risco, favorecer o desenvolvimento de ações intersetoriais, promover a participação da comunidade, e humanizar as práticas de saúde (Brasil, 1998).

Nesse sentido, em 2000, ocorre outro fato importante para a saúde pública. Com a publicação da Portaria 1.444, de 28 de março do referido ano, a odontologia passa também a ser incluída na estratégia do PSF, com repasse de recursos para os municípios financiarem essa inserção. Este fato representa a ampliação dos serviços de atenção básica e o reconhecimento do direito da população à saúde bucal. Como, também, a possibilidade da criação de um novo espaço de práticas e relações, reorientando o processo de trabalho do dentista, bem como a própria forma de atuar da odontologia dentro dos serviços de saúde (Brasil, 2004a).

A inclusão do cirurgião-dentista no PSF representa maior possibilidade de acesso de milhões de brasileiros a um serviço de saúde bucal, além de trazer o dentista para mais perto da população, fazendo-o repensar sua prática a partir da reorganização do modelo de atenção. De acordo com a Portaria № 267 de março de 2001, que dispõe sobre normas e diretrizes de inclusão da saúde bucal na estratégia do PSF, as ações de saúde bucal devem expressar, como características operacionais, entre outras: o caráter substitutivo das práticas tradicionais, a definição da família como centro da abordagem da equipe e a humanização do atendimento (Brasil, 2001).

Dessa forma, o PSF promove uma mudança no processo de trabalho do profissional da saúde, por meio de uma nova forma de "intercessão partilhada", agora estabelecida não só mais entre profissional e usuário, mas também entre o serviço e a família/comunidade. Torna-se importante, então, a utilização das tecnologias leves, de que fala Merhy (2007a, b; 2004), dentro da produção dos atos em saúde, com a consequente valorização de dispositivos como o vínculo e o acolhimento. O primeiro, o vínculo, transformou-se em uma meta da ação do PSF, e o último, o acolhimento, é discutido pela Política Nacional de Humanização (PNH), lançada pelo MS em 2004, e que busca a valorização do sujeito dentro do SUS, seja ele usuário, profissional ou gestor (Brasil, 2008b).

Nesse sentido, ao se refletir sobre as tecnologias leves, observa-se que o campo do trabalho em saúde possui características particulares por se encontrar no setor de serviços e tratar de uma realidade que lida diretamente com as necessidades e expectativas do sujeito/usuário. Sendo assim, toda ação assistencial de um profissional de saúde junto a um usuário realiza-se através de um trabalho vivo em ato, por meio do qual há o encontro de duas pessoas, atuando uma sobre a outra em um processo relacional (Merhy, 2004).

Nesse espaço de encontro, atuam as tecnologias leves combinadas aos outros dois tipos de tecnologias, isto é, tanto ao aparato tecnológico (tecnologia dura), como, também, ao conjunto de saberes estruturados e organizados (tecnologia leve-dura). Porém, cabe às tecnologias leves comandarem os modos de incorporação das demais, abrindo, assim, caminho para se repensar o processo de produção da subjetividade no interior das práticas de saúde, em vista de atingir uma maior qualidade da atenção (Merhy, 2007b).

O cirurgião-dentista depara-se com essas diversas tecnologias no sentido da construção do cuidado. É fácil identificar que, devido às características próprias de sua prática, esse profissional encontra-se 
dependente das tecnologias duras, como os instrumentais e equipamentos presentes no consultório odontológico. Porém nunca poderá prescindir das tecnologias leve-duras e das tecnologias leves, já que opera também no espaço do encontro com o usuário. É o somatório dessas tecnologias que comporá o cuidado no atendimento odontológico.

Vale, ainda, esclarecer que, nesse espaço de encontro construído entre profissional e usuário, ambos trarão e partilharão suas próprias expectativas, necessidades e desejos, de forma singular. Dessa maneira, esse espaço também se caracterizará como um lugar de conflitos e disputas, em alguns momentos, devendo ser também, assim, um lugar de vozes e escutas, onde todos os sujeitos envolvidos precisam ser considerados em suas necessidades (Merhy, 2007a).

O dentista encontra-se com o outro, o usuário, construindo com ele um espaço de intercessão frequentemente marcado pela dor, pela ansiedade e pelo sofrimento desse usuário, que deseja ser compreendido e atendido em suas necessidades - daí a relevância das tecnologias leves na prática do cirurgião-dentista. Dentre essas tecnologias, destacam-se, aqui, o acolhimento e o vínculo, dois conceitos que se complementam na construção de um cuidado humanizado na saúde (Merhy, 1997).

Esses instrumentos possuem diferentes enfoques, os quais são abordados tanto na literatura como na prática do serviço. O acolhimento, por exemplo, segundo Merhy (2004), adquiriu uma dupla dimensão, sendo, de um lado, considerado como parte de uma etapa do processo de trabalho, sobretudo no momento da recepção dos serviços de saúde, relacionando-se ao primeiro contato com o usuário. E, de outro lado, como um dispositivo do processo intercessor do trabalho em saúde, necessário em todos os lugares em que se deem os encontros entre trabalhador e usuário.

Teixeira (2005) corrobora com esta discussão ao afirmar que o acolhimento é bem mais que uma atividade de recepção no serviço, atribuída a um determinado profissional em um espaço físico específico. Para o autor, trata-se de uma técnica de conversa que pode ser efetuada em qualquer momento do atendimento e que auxilia no conhecimento das necessidades dos usuários a serem satisfeitas.

Dessa forma, outra ferramenta compatível com a ideia das tecnologias leves e importante no sentido da humanização da atenção à saúde refere-se ao vínculo. Instrumento importante e privilegiado dentro da estratégia do PSF, o vínculo busca promover a criação de laços de compromisso e de corresponsabilidade entre os profissionais da equipe e a população da área de cobertura que está sob sua responsabilidade, permitindo uma maior aproximação entre serviço e comunidade (Brasil, 1998).

Porém, como afirma Silveira Filho (2002), o vínculo vai além do estabelecimento de um simples contato com a população de uma determinada área ou de um simples cadastro. Ele exige uma real aproximação do profissional com a realidade vivenciada pelo usuário dentro de seu contexto social para que possa compreender suas condições de vida e suas verdadeiras demandas, comprometendo-se com elas.

De acordo com o pensamento de Silva Junior e Mascarenhas (2004), o vínculo possui três dimensões: da afetividade, da relação terapêutica e da continuidade. Conforme a primeira, o profissional da saúde deve gostar de sua profissão, interessando-se pela pessoa do paciente, como diz o autor, para então construir um vínculo com ele. Na segunda dimensão, a própria relação entre ambos, profissional e paciente, é vista como terapêutica, por intermédio da qual o paciente é considerado sujeito no processo de tratamento e na qual se desenvolve o sentimento de confiança entre ele e o profissional. E, na terceira dimensão, a continuidade do processo terapêutico é apontada como fortalecedora do vínculo e do mútuo sentimento de confiança entre profissional e paciente.

Desse modo, o objetivo deste estudo é compreender como tem se dado a construção dos dispositivos do acolhimento e do vínculo no encontro entre o cirurgião-dentista e o usuário, no sentido de se construir uma prática mais humanizada de atenção à saúde bucal no PSF de Fortaleza. Nesse sentido, surgem algumas questões norteadoras, como: qual atenção tem sido dada para o processo de acolhimento do usuário por parte do cirurgião-dentista? E o vínculo, como este tem sido construído entre o usuário e o odontólogo?

\section{Metodologia}

Trata-se de uma pesquisa qualitativa, de natureza explicativa, que foi realizada no município de Fortaleza, no estado do Ceará. Este município possui uma população estimada, em agosto de 2009, de 
2.505.552 habitantes, segundo o Instituto Brasileiro de Geografia e Pesquisa - IBGE (Brasil, 2009), e encontra-se atualmente dividido, em termos administrativos, em seis Secretarias Executivas Regionais. Estas funcionam como instâncias executoras das políticas públicas municipais, sendo cada uma delas composta, entre outros setores, por um Distrito de Saúde. Em dezembro de 2006, segundo dados do Relatório de Gestão do município (Fortaleza, 2007), encontravam-se em funcionamento 304 equipes de PSF e 233 Equipes de Saúde Bucal (ESB).

Sendo assim, diante do objetivo proposto para este estudo, foram escolhidos, como sujeitos desta pesquisa, cirurgiões-dentistas, selecionados das seis regionais de Fortaleza, de modo que todas fossem representadas nesta pesquisa, respeitando, assim, as diferenças existentes entre elas.

Os cirurgiões-dentistas escolhidos deveriam responder, simultaneamente, a dois critérios: atualmente encontrar-se trabalhando em uma das ESBs de Fortaleza e haver trabalhado, no sistema público de saúde deste município, num período anterior ao concurso realizado em 2006, ou seja, antes da implantação das equipes de saúde bucal no PSF. Esta escolha teve por finalidade compreender as diferenças trazidas, através desta estratégia de reorganização do sistema de saúde, que é o PSF, para a prática do cirurgião-dentista, no sentido da humanização da atenção à saúde bucal.

Para se alcançar tal fim, primeiramente, foi realizada uma pesquisa junto à SMS de Fortaleza e à cooperativa responsável pela contratação dos odontólogos antes do concurso. Dessa forma, puderam ser obtidas informações sobre quem são e onde se encontram, hoje, alocados os cirurgiões-dentistas que se encaixam nos requisitos estabelecidos anteriormente.

Naquelas Regionais em que se encontraram mais de dois dentistas que correspondiam aos critérios mencionados para inclusão destes nesta pesquisa, a seleção dos que seriam entrevistados se deu levando em consideração o acesso ao odontólogo e sua disponibilidade em participar da pesquisa. $O$ número final de entrevistas foi estabelecido considerando-se a saturação teórico-empírica e a relevância das informações (Gaskell, Bauer, 2002), somando um total de 16 sujeitos.

Para a coleta dos dados, um dos instrumentos utilizados foi a entrevista semiestruturada. As entrevistas foram gravadas por meio de equipamento de áudio e transcritas integralmente, sendo mantida em sigilo a identidade dos entrevistados, obedecendo-se, assim, às Diretrizes e Normas Regulamentadoras de Pesquisa envolvendo seres humanos, aprovadas pelo Conselho Nacional de Saúde, por meio da Resolução 196/1996 (Brasil, 1996). Seguindo as mesmas diretrizes, a pesquisa foi submetida e aprovada pelo Comitê de Ética da Universidade Estadual do Ceará.

Foi utilizada, também, a técnica da observação simples, aplicada durante as visitas às unidades de saúde para a realização das entrevistas com os dentistas selecionados, visto que tais entrevistas aconteceram no próprio local de trabalho destes profissionais. Por meio das observações feitas, puderam ser colhidas informações importantes, especialmente a respeito de questões estruturais e ambientais dos centros de saúde, como a existência de espaços adequados para a realização do acolhimento quando da recepção dos usuários no serviço, bem como a ambiência da unidade de saúde - fator também destacado pela PNH (Brasil, 2008b), tendo em vista a humanização dos serviços de saúde. Todas essas informações foram devidamente registradas em diário de campo.

Com base nos instrumentos referidos e apoiados pelo referencial teórico, promoveu-se o diálogo entre os dados coletados, teóricos e práticos, por meio da triangulação dos métodos, como referido por Souza et al. (2005).

Para o tratamento dos dados, foi escolhido o método de análise de conteúdo, por esta técnica permitir, depois de uma leitura de primeiro plano das falas, atingir níveis mais aprofundados de compreensão da mensagem (Minayo, 2007).

Em uma leitura sobre a técnica de análise de conteúdo, com base em autores como Berelson e Bardin, entre outros, Minayo (2007) classifica diferentes formas da análise de conteúdo. Para este estudo, fez-se a opção pela análise temática que, segundo a mesma autora, permite a identificação da existência de temas ou núcleos de sentido em uma mensagem, cuja presença ou frequência apresentem significância no conteúdo das análises, e que se apresenta como adequada às pesquisas qualitativas em saúde.

Sendo assim, as entrevistas foram transcritas fielmente, respeitando-se as nuances das falas dos entrevistados. Só então foram feitas leituras exaustivas destas no intuito de se identificarem os núcleos de sentido, tomando-se como ponto de partida, para tal, os objetivos do estudo e as perguntas realizadas durante as entrevistas. 
Dessa forma, a análise seguiu três momentos: a pré-análise, a exploração do material e o tratamento e a interpretação dos resultados obtidos. Durante a exploração do material, os núcleos de sentido selecionados foram: acolhimento, vínculo, humanização, processo de trabalho no PSF e dificuldades. A partir destes núcleos, foram feitos recortes nas falas dos entrevistados e, com esses recortes, montou-se um quadro onde foi realizada tanto uma síntese horizontal como vertical do que havia sido dito sobre cada tema, levando-se em consideração os pontos convergentes e divergentes presentes nos depoimentos dos entrevistados. Com base nestes pontos, puderam ser construídas categorias de análises, organizando o conteúdo presente nas falas.

Depois deste processo, foram realizadas a interpretação e as inferências, com base no referencial teórico construído anteriormente e na análise dos documentos oficiais do governo. A escolha destes documentos foi realizada de acordo com as necessidades que surgiam a partir dos núcleos temáticos selecionados. Foi realizada uma leitura de cada um, buscando-se interpretar os conteúdos manifestos e latentes, relacionando-os com as categorias escolhidas. As informações extraídas foram, então, cruzadas com a análise feita nas falas dos sujeitos do estudo.

\section{Acolhimento e vínculo na prática do cirurgião-dentista no PSF}

Dessa maneira, por meio da análise das entrevistas, observa-se a importância do uso das tecnologias leves no processo de trabalho do cirurgião-dentista para a humanização da sua prática, bem como para a obtenção de um cuidado mais integral na estratégia do PSF. Essa importância fica clara tanto nas falas que ressaltam uma maior valorização que essas tecnologias têm no momento de encontro entre cirurgião-dentista e usuário, como naquelas que relatam sobre a sua ausência e a necessidade de uma maior utilização destas no dia a dia do serviço.

O acolhimento, em todas as entrevistas analisadas, encontra-se identificado com um dos sentidos presentes no discurso de Merhy (2004), isto é, ora como um dispositivo intercessor do trabalho em saúde, que pode ser representado por uma postura ou atitude de escuta e diálogo entre profissional e usuário, ora como apenas uma primeira etapa do processo de trabalho, associada à recepção ou à triagem administrativa. Porém, fica também claro que, na maioria das entrevistas, isto é, em 13 das 16, a definição que primeiro surge e que prevalece na fala do cirurgião-dentista é a do acolhimento como uma etapa do processo de trabalho, geralmente reconhecida como ação de triagem ou classificação de risco, além do próprio agendamento.

"A gente faz essa triagem no dia da marcação, é o que a gente chama de acolhimento [...] as pessoas que estão aqui para marcar, a gente faz o acolhimento, vendo quem tá necessitando mais". (E3)

"Então, no final das contas acaba sendo mesmo uma triagem, quem vai ser atendido e quem não vai, existe até prioridade para isso". (E13)

Isso indica, de uma forma geral, um esvaziamento ou empobrecimento do sentido mais amplo do que seja acolhimento por parte dos profissionais entrevistados, que centram suas respostas em apenas um dos aspectos do acolhimento, isto é, enquanto dispositivo técnico assistencial de organização do processo de trabalho. Este fato já tinha sido identificado por Teixeira (2003, p.98), ao afirmar que:

As soluções práticas que temos conhecido ultimamente para a questão do acolhimento na atenção primária, principalmente em unidade de PSF, tendem a concebê-la como uma atividade particularizada, que realizaria a combinação de alguns dispositivos organizacionais tradicionais dos serviços de saúde (recepção, triagem, acesso). Em muitos casos, tende a sofrer deslocamentos (acesso, porta de entrada, pronto-atendimento), que vão até o limite de esvaziá-la de significado próprio, sendo apenas um nome novo para uma velha atividade.

Vale lembrar aqui, também, a diferença entre triagem e técnica de avaliação com classificação de risco propriamente dita e recomendada como dispositivo da $\mathrm{PNH}$. No acolhimento com avaliação de risco, recomenda-se a avaliação do grau de sofrimento do usuário que chega ao sistema de saúde, considerando, neste sofrimento, tanto a vertente física como a psíquica (Brasil, 2008a). 
Posterior a essa avaliação, segue-se a identificação daqueles usuários que necessitam de algum tipo de tratamento imediato, com a priorização destes em relação à assistência ou o seu encaminhamento a outros níveis de atenção quando necessário. Essa forma de acolhimento implica, então, a necessidade de uma escuta qualificada das queixas e sofrimentos trazidos pelo usuário, além da busca por uma responsabilização e resolutividade dos problemas apresentados por este (Teixeira, 2005).

Sendo assim, a função da porta de entrada do sistema não é mais barrar e limitar o atendimento, mas dar uma resposta aos problemas de modo criativo, utilizando as tecnologias leves disponíveis (Merhy, 1997). Isto é, diferente da triagem, que traz a ideia apenas de uma seleção, escolha de quem vai ou não ser atendido de acordo com algum critério preestabelecido, no acolhimento, enquanto avaliação com classificação de risco, todos os usuários que procuram o serviço de saúde por demanda espontânea devem ter uma resposta de acordo com sua necessidade e com a oferta de serviço disponível (Brasil, 2008a).

Assim, essa é outra ideia que se destaca, na fala dos entrevistados, e que se relaciona à definição de acolhimento enquanto classificação de risco como sendo a mesma coisa que triagem. Isso pode ser tanto um reflexo das práticas tradicionais, que tinham, na triagem, um dispositivo de seleção dos que seriam atendidos, como um dos problemas ainda existentes quanto à referência entre os níveis de atenção.

Essa realidade, presente ainda hoje no dia a dia dos Centros de Saúde da Família (CSFs), acaba por conceder um caráter realmente de seleção à técnica de classificação de risco, ou seja, são escolhidos aqueles casos para os quais o serviço pode dar uma resposta, sendo encaminhados, sem esperança de retorno, aqueles que necessitam de uma atenção mais especializada.

Contudo, é necessário reconhecer, também, que o acolhimento, enquanto ferramenta tecnológica de intervenção, pautado em uma busca pela universalidade do acesso e na avaliação de risco com definição de prioridades, já representa um importante avanço no sentido da humanização da atenção. Ao voltarmos um pouco na história, na maior parte dos antigos postos de saúde encontrava-se a precária situação do acesso organizado burocraticamente a partir das filas por ordem de chegada, que privilegiavam não aqueles que necessitavam, de forma mais urgente, de assistência, mas os que se mostravam mais resistentes ou aqueles que conseguiam comprar uma ficha - como lembra o entrevistado a seguir:
"Quem trabalhava antes de quando começou o acolhimento via, tinha aquela velha história, de pedra, de venda de ficha [ ...] Aí, quem chegava de madrugada, era quem tava na frente e então pegava as primeiras vagas e o resto ficava para depois. Aí nunca tinha vaga para ninguém, a agenda sempre cheia, e assim não. Você vai na segunda, se o caso tiver grave, é agendado na segunda, se não é, fica pro final da semana". (E1)

Outro ponto importante percebido ainda é que o acolhimento, enquanto técnica de avaliação e classificação de risco, representa uma prática recente dentro do SUS e, como tal, ainda não conseguiu se organizar em todos os CSFs da mesma forma, o que tem gerado, na prática, certos pontos de tensão, necessitando ainda de alguns ajustes. De acordo com os profissionais entrevistados, tais dificuldades, geralmente, encontram-se relacionadas: à grande demanda, à falta de um lugar adequado para a realização dos exames de classificação de necessidade, e à própria técnica em si, que precisa ser adaptada a cada realidade.

"Nesse posto não tem acolhimento porque a população dele é gigantesca, são quase 100.000 habitantes". (E5)

"A gente quer mudar a metodologia agora do acolhimento [...] A nossa marcação de consulta está um pouco estressante para nós profissionais. A triagem toma muito tempo porque você examina 30 pessoas numa manhã e ali você explica as coisas, você termina umas nove, nove e meia e, depois, ainda tem os pacientes para atender [...] E aí, com a mudança que a gente quer fazer, a gente quer tirar esse acolhimento diário". (E15)

Por se encontrar ainda em fase inicial, esse processo de acolhimento, nos CSFs visitados, tem produzido ruídos que se manifestam no meio da relação entre profissional e usuário. A técnica do acolhimento tem gerado, por exemplo, a sobrecarga de trabalho para os odontólogos, já que estes 
precisam dar conta dos usuários agendados, das urgências, além de realizarem a classificação de risco dos usuários que chegam à unidade de saúde. Fora isso, tem sido também fonte de insatisfação do usuário, com o processo de trabalho, a organização da demanda realizada pela equipe e consequente falta de acesso ao serviço.

Tal situação é comentada no documento Acolhimento com classificação de risco da PNH (Brasil, 2004b), quando esse se refere aos questionamentos que podem surgir por usuários que se sentiriam prejudicados dentro dessa lógica de organização do sistema, que busca priorizar quem apresenta uma maior classificação de risco. Como solução para esse problema, o documento sugere a explicação desse dispositivo para os usuários na sala de espera, ou seja, ele prevê a utilização do próprio dispositivo como solução, já que esta técnica deve lançar mão da escuta e do diálogo com o usuário na tentativa de fazê-lo compreender a nova proposta de organização da demanda. Contudo, essa solução é insuficiente para responder à falta efetiva do sistema em atender a todos, conforme definido constitucionalmente, pois o número de equipes de saúde bucal é insuficiente para atender à população adscrita e àquela de áreas descobertas.

Dessa maneira, em determinados momentos, é necessário entender que os ruídos provenientes dos momentos de tensão, vividos por profissionais e usuários, são pistas importantes a respeito de como se encontra organizado o processo de trabalho em saúde. Sendo assim, devem ser avaliados para que novos rumos possam ser pensados; lembrando-se, ainda, que a solução nem sempre é simples e, em diversos momentos, escapa à capacidade do profissional de resolver o problema, pois este, em várias situações, corresponde a dificuldades e desafios estruturais do próprio sistema de saúde.

Diante dessa situação, vale destacar a presença desses processos ruidosos nos serviços de saúde, pois eles surgem e operam em busca de novos caminhos, como linhas de fuga do que se encontra estabelecido. Isto é, caso o modelo assistencial não permita a expressão de um desses sujeitos, sempre aparecerão, de alguma forma, certos ruídos, representados tantas vezes por fissuras ou disfunções no processo de trabalho, que devem ser percebidos pelo profissional e pelos gestores, abrindo possibilidades para uma nova forma de gerir e operar o trabalho em saúde (Merhy, 2004).

Precisa-se, então, tomar cuidado para que o dispositivo do acolhimento venha a atuar como meio de escuta e diálogo entre os sujeitos, e não como instrumento silenciador de uma situação que requer mudanças. O profissional também não deve querer exercer o papel de "disciplinador" de certas condutas dos usuários, mas deve, sim, tomar consciência dos desafios existentes e de seu importante papel como transformador dessa realidade.

Diante disso, confirma-se a necessidade de o acolhimento ser entendido para além da técnica de classificação de risco, sendo capaz, também, de fazer um reconhecimento das sinuosidades tensionais, presentes nos vários momentos de encontro entre profissionais da saúde e usuários. Ele deve ser capaz de estabelecer novas comunicações que, por sua vez, sejam capazes de produzir técnicas terapêuticas centradas no sujeito que demanda por cuidado (Santos, 2005).

Para a qualificação da escuta e aplicação da classificação de risco, foram realizados alguns cursos de capacitação no que se refere à PNH, promovidos pela secretaria municipal de saúde de Fortaleza. Esse processo iniciou-se com o Curso de Extensão Universitária Fortaleza HumanizaSUS, realizado em duas etapas. Após, aconteceram oficinas sobre o acolhimento nas regionais que compõem o município de Fortaleza, além de outros encontros realizados em alguns centros de saúde, como destaca o entrevistado:

"Os cursos falam muito no acolhimento, em relação a humanização. Foi feito em todas as unidades, para mostrar o que é o acolhimento, que tem que tratar bem [...]. É batido muito nessa tecla do acolhimento. E o acolhimento é toda hora". (E15)

Sobre esse assunto, percebe-se que a visão mais ampla do acolhimento - como diretriz que deve estar presente em todos os momentos dos processos de saúde, produzindo escuta e diálogo entre profissional e usuário - também se faz presente nos cursos de capacitação oferecidos.

Sendo assim, apoiados pelos documentos do próprio MS, que tratam sobre o acolhimento (Brasil, 2008a; 2004b) e que abordam o seu caráter sistemático enquanto técnica constituinte do processo de trabalho em saúde, sugere-se que uma possível explicação para a maior presença desse sentido, relacionado à organização da demanda, em detrimento do outro, relacionado a uma postura de escuta e diálogo, na fala dos profissionais, seja a necessidade de sistematização de atividades para sua concretização. Ou seja, pela preocupação do cirurgião-dentista em apreender esse processo e por este 
mesmo se referir a um dos pontos de maior conflito dentro do CSF, associado diretamente ao acesso do usuário ao serviço de saúde, este profissional acaba por centrar suas colocações e atenções no conceito restrito do acolhimento como classificação de risco.

Assim como o acolhimento, o vínculo é outra tecnologia leve importante dentro da prática do PSF e que tem contribuído para a mudança do modelo assistencial, não mais centrado na doença, mas no sujeito. Dessa forma, embora a implantação do PSF seja ainda um processo em construção - até mesmo porque em fase de recente implantação na história do sistema de saúde - pode-se reconhecer, entretanto, que certo vínculo começa a ser construído na realidade das ESBs implantadas em Fortaleza. Essa percepção advém do que foi observado nas entrevistas realizadas e que apontam para diferentes enfoques em relação a este tema:

“Tem casos de família que a gente sabe onde mora, sabe os problemas, problema com o marido, problema de saúde, uma dificuldade financeira que às vezes dificulta no tratamento ser positivo, então a gente tem que conhecer todas essas dificuldades para poder saber a realidade do nosso paciente". (E11)

No primeiro enfoque, apresentado pelo entrevistado onze, o vínculo associa-se a um olhar mais amplo e integral do problema relatado pelo usuário, considerando, para isso, diversos aspectos que podem influir no processo saúde-doença-cuidado. Essa visão se faz possível a partir de uma maior aproximação que esse profissional parece estabelecer com o usuário.

Neste sentido, Santos (2005, p.39) defende a necessidade do contato íntimo do profissional de saúde com o cotidiano das pessoas, a partir de uma clínica que vá além da unidade de saúde, "buscando conhecer e compreender o indivíduo, a família e a comunidade, no espaço concreto de suas relações".

A partir dessa discussão, toca-se aqui em outro ponto importante e correspondente ao segundo enfoque, encontrado na fala dos entrevistados, sobre o vínculo, no que se refere a este como uma relação de amizade que se constrói entre os sujeitos envolvidos no processo terapêutico.

“Eu sei hoje o nome dos meus pacientes todos, quase todos. Sei os problemas deles, não só odontológicos, sei da vida deles [...] eu tento ser o mais humano possível [...] Trato eles como fosse meus colegas, meus amigos. Converso, falo da vida com todos". (E7)

Neste enfoque, fica claro também, em relação ao vínculo, a importância dada pelo profissional à questão da pessoalidade presente na relação entre ele e o usuário. Pessoalidade esta marcada pelo conhecimento tanto do nome de cada pessoa, como também dos problemas de cada uma.

Outro importante e último enfoque encontrado é aquele que associa diretamente o vínculo à continuidade do tratamento e à relação de confiança criada entre profissional e usuário.

“Esse paciente é sempre acompanhado, a gente tá sempre desenvolvendo atividades com ele, tanto clinica como coletiva [...] Ele passa a confiar mais naquilo em que você está dizendo [...] assim, quando ele recebe alta clinica, ele tem a certeza de que, daqui a seis meses, vai tá retornando pra gente. Então, ele fica sendo acompanhado pelo mesmo profissional. Eu acho que isso é muito importante para a questão da confiança". (E9)

O usuário não vai mais para qualquer profissional, mas para aquele que ele já conhece e confia. Nesse sentido, Gomes e Pinheiro (2005) acrescentam que o vínculo tem a capacidade de atuar no desenvolvimento de uma responsabilização e compromisso da equipe/profissional com a comunidade/ usuário, através dos quais se dão relações de troca e confiança.

Para a efetivação desta nova proposta trazida pelo PSF, entretanto, uma importante dificuldade se apresenta, segundo os entrevistados, referente ao número de pessoas vinculadas a cada equipe de saúde bucal. Fica evidente que a grande demanda tem dificultado a criação do vínculo entre profissional e usuário. Os profissionais entrevistados deixam claro que nem sempre é possível reconhecer cada pessoa pelo nome ou reconhecer a fisionomia dela, sendo mais fácil, em muitos momentos, reconhecer 
as condições bucais de saúde ou doença, fato que nos relembra que a relação estabelecida pelo odontólogo nem sempre foi com um sujeito, mas apenas com os dentes deste.

\footnotetext{
"Não é o ideal porque ainda não é aquela coisa que a gente reconhece a pessoa pelo nome, às vezes reconhece quando olha a boca é que lembra "ah, você já veio aqui", por conta da quantidade de pessoas". (E12)
}

Discutidos, assim, os enfoques e dificuldades referentes ao estabelecimento do vínculo, cabe aqui a análise, ainda, de um instrumento de destaque dentro da prática do PSF, que são as visitas domiciliares, importante meio de aproximação do profissional com a realidade vivenciada pelo usuário, bem como, consequentemente, de construção dessa relação de amizade e confiança baseada no vínculo.

Nesse sentido, vale ressaltar o que nos coloca a Portaria n.267 (Brasil, 2001), quando define, como uma das atribuições comuns a todos os profissionais de saúde bucal do PSF, a realização das visitas domiciliares. Porém, na realidade das ESBs do município de Fortaleza, não se percebe uma priorização desse instrumento.

Este fato se deve, segundo relatado nas entrevistas, tanto à infraestrutura, no que se refere à falta de transporte - pois a realidade da maioria dos PSF's é a de somente um carro para toda a equipe, o que faz com que nem sempre tenha vaga para o odontólogo -, como também à organização do trabalho do cirurgião-dentista dentro dos CSFs. A falta de tempo para outras atividades, além da clínica, devido à grande demanda existente e ao pequeno número de profissionais contratados, tem feito com que o cirurgião-dentista concentre, ainda, suas ações somente no consultório odontológico, o que tem dificultado a construção do vínculo, que, por sua vez, poderia ser mais facilmente estabelecido em outros espaços, como por meio das visitas domiciliares.

\footnotetext{
"Antes do concurso, que a gente implantou o PSF, eu tive uma facilidade maior com a criação desse vinculo. Hoje em dia não, como tem a clinica, você tem essa criação de vinculo, mas é mais lento. Por exemplo, hoje eu não vou te dizer que eu conheço todos os meus pacientes da área porque eu não conheço [...] Antes do concurso, era uma cadeira para dois dentistas, então tinha muito mais tempo para fazer outras atividades, outros grupos, de fazer visita".

Diante desta realidade, vale lembrar o que nos diz Silveira Filho (2002), ao afirmar que o vínculo se estabelece a partir do acompanhamento das famílias, tendo a visita, para isso, um valor tão grande quanto o diagnóstico clínico de uma determinada patologia, permitindo ações tanto de promoção, prevenção, tratamento, como também de suporte às mudanças comportamentais na família.

Apesar das dificuldades, porém, não se pode deixar de registrar que o PSF fortaleceu a importância do vínculo como instrumento facilitador das relações e do próprio processo de trabalho em cada CSF visitado, pois, embora não podendo identificar uma mesma importância conferida à questão do vínculo por parte de todos os cirurgiões-dentistas entrevistados, percebe-se já uma maior presença desse tema nas falas e nas discussões trazidas por esse profissional.

Acreditamos que só podemos transformar o processo de produção da saúde se o centrarmos no sujeito. O acolhimento e o vínculo constituem, então, importantes instrumentos na mudança desse olhar que, por tanto tempo, se centrou somente no processo patológico da doença, esquecendo o sujeito e outros fatores, como os psicossociais, tão importantes na determinação do diagnóstico e plano terapêutico.

\section{Considerações finais}

As tecnologias leves constituem instrumento fundamental para transformação das práticas em saúde, tantas vezes centradas na doença e no aparato tecnológico de equipamentos e saberes especializados que prometiam a cura sem considerar, entretanto, o sujeito. Ou seja, o mecanismo e o processo terapêutico adotados eram iguais para todas as pessoas que possuíam o mesmo diagnóstico, 
independente do contexto social em que estavam inseridas e sem se considerarem os dispositivos relacionais que poderiam mediar todo planejamento e execução dos atos em saúde.

O PSF, nesse sentido, apresenta-se como uma estratégia que possibilita um maior desenvolvimento e atuação dessas tecnologias leves, já que se propõe a desenvolver um trabalho mais próximo à comunidade e à família. Dessa forma, percebe-se que, na tentativa de melhor adequar seu trabalho ao proposto pelo PSF, o odontólogo, aos poucos, tem buscado fazer maior uso, em sua prática, de tais tecnologias, como o acolhimento e o vínculo, dando, assim, uma maior importância à construção da relação entre ele e o usuário do sistema.

Entretanto, na fala dos entrevistados, identifica-se que o acolhimento apresenta-se mais relacionado como uma primeira etapa de organização do processo de trabalho no PSF, sendo associado, em muitos momentos, com a ideia de triagem. $\mathrm{O}$ acolhimento, de acordo com esse entendimento, aparece como prática ainda nova e que tem se estruturado de forma diferente nas diversas unidades de saúde, gerando ruídos e descontentamento por parte de profissionais e usuários.

Enquanto isso, a concepção mais ampla do acolhimento, associada a uma atitude e postura de escuta, não se apresenta de forma tão marcante nas falas dos entrevistados, encontrando-se, contudo, essa ideia relacionada à questão do vínculo. Este, por sua vez, possui também outros enfoques, entre os entrevistados, relacionados à questão da amizade estabelecida entre profissional e usuário e a relação de confiança estabelecida entre esses sujeitos, importante na continuidade do tratamento.

Os dois conceitos, do acolhimento e do vínculo, são complementares e acredita-se, por isso, que, embora a visão sobre o primeiro precise ainda ser ampliada junto aos cirurgiões-dentistas entrevistados, a preocupação crescente com a construção do vínculo tem ajudado a transformar, aos poucos, a realidade antes existente no sistema de saúde, representada pela distância entre usuário e profissional.

As mudanças precisam ser comemoradas, sem, contudo, serem esquecidos os problemas que ainda se apresentam na prática dos serviços de saúde, como a grande demanda que chega, todos os dias, aos CSF's e que tem sido responsável por importantes linhas de tensão na prática do odontólogo. A maioria das ESBs ainda é responsável por uma população grande, não conseguindo, assim, conhecer a realidade das pessoas de sua área de trabalho, nem estabelecer com elas uma verdadeira aproximação. Essa demanda tem forçado o odontólogo, ainda, a uma prática presa ao consultório, impedindo-o de utilizar outros espaços importantes, como o das visitas domiciliares. Estas, por sua vez, acontecem de forma esporádica também por outro motivo, que é o da falta de transporte.

Diante de tais dificuldades, fazem-se necessários uma discussão e aprofundamento cada vez maiores sobre o assunto já que o novo modelo de assistência sugerido pelo PSF requer o uso das tecnologias leves. Dessa forma, considera-se importante reforçar o conceito do acolhimento como postura e atitude de escuta e diálogo nos cursos de capacitação da PNH, isto é, enquanto diretriz que deve perpassar todos os momentos de produção da saúde, sendo necessária, para isso, a promoção de reflexões coletivas sobre o assunto que se estendam para o dia a dia dos centros de saúde, sendo tema das rodas e dos grupos realizados.

Acredita-se, também, que a inserção das visitas domiciliares, como uma atividade mais frequente do cirurgião-dentista no PSF, seria um instrumento importante na aproximação deste sujeito com a realidade do usuário e da comunidade. Porém, para isso, faz-se necessário um maior número de carros para o transporte dos profissionais e uma melhor divisão do trabalho do cirurgião-dentista.

Já que, até então, muito se apostou na ação das tecnologias duras e leve-duras para a construção do modelo biomédico, conclui-se, com base nas ideias de Merhy, que um grande campo ainda existe, em termos de tecnologias leves ou relacionais, a ser explorado como potencial para a mudança do processo de trabalho na saúde, passando este de uma posição centrada em procedimentos a uma outra centrada no usuário.

\section{Colaboradores}

Os autores trabalharam juntos em todas as etapas de produção do manuscrito. 


\section{Referências}

BRASIL. Ministério do Planejamento, Orçamento e Gestão. Instituto Brasileiro de Geografia e Pesquisa. Estimativas das populações dos municípios em 2009. 2009. Disponível em: <http://www.ibge.gov.br/home/estatistica/populacao/estimativa2009>. Acesso em: 1 dez. 2009.

. Ministério da Saúde. Secretaria de Atenção à Saúde. Núcleo Técnico da Política Nacional de Humanização. Acolhimento nas práticas de produção de saúde. 2.ed. Brasília: MS, 2008a.

- Ministério da Saúde. Secretaria de Atenção à Saúde. Núcleo Técnico da Política Nacional de Humanização. HumanizaSus: documento base para gestores e trabalhadores do SUS. 4.ed. Brasília: MS, 2008b.

Ministério da Saúde. Secretaria de Atenção à Saúde. Departamento de Atenção Básica. Coordenação Nacional de Saúde Bucal. Diretrizes da Política Nacional de Saúde Bucal. Brasília: MS, 2004a.

. Ministério da Saúde. Secretaria Executiva. Núcleo Técnico da Política Nacional de Humanização. HumanizaSUS - acolhimento com classificação de risco: um paradigma ético-estético no fazer em saúde. Brasília: MS, 2004b.

Ministério da Saúde. Portaria n.267/GM, de 6 de março de 2001. Dispõe sobre normas e diretrizes da inclusão da saúde bucal na estratégia do Programa Saúde da Família. Diário Oficial da República Federativa do Brasil, Brasília, DF, 6 mar. 2001, seção 1, p.67.

Ministério da Saúde. Secretaria de Assistência à Saúde. Coordenação de Saúde da Comunidade. Saúde da Família: uma estratégia para a reorientação do modelo assistencial. Brasília: MS, 1998.

Conselho Nacional de Saúde. Resolução n.196 de 10 de outubro de 1996. Dispõe sobre normas para pesquisa envolvendo seres humanos. Diário Oficial da República Federativa do Brasil, Brasília, DF, 10 de outubro de 1996 Seção 1, p.4-6.

FORTALEZA. Secretaria Municipal de Saúde. Relatório de gestão do ano de 2006 da Secretaria Municipal de Saúde de Fortaleza: saúde, qualidade de vida e a ética do cuidado. Fortaleza: SMS, 2007.

GASKELL, G.; BAUER, M.W. Para uma prestação de contas públicas: além da amostra, da fidedignidade e da validade. In: BAUER, M.W.; GASKELL, G. (Orgs.). Pesquisa qualitativa com texto, imagem e som: manual prático. Petrópolis: Vozes, 2002. p.470-90.

GOMES, M.C.P.A.; PINHEIRO, R. Acolhimento e vínculo: práticas de integralidade na gestão do cuidado em saúde em grandes centros urbanos. Interface - Comunic., Saude, Educ., v.9, n.17, p.287-301, 2005.

MERHY, E.E. Em busca do tempo perdido: a micropolítica do trabalho vivo em saúde. In: MERHY, E.E.; ONOCKO, R. (Orgs). Agir em saúde: um desafio para o público. 3.ed. São Paulo: Hucitec, 2007a. p.71-112.

Saúde: a cartografia do trabalho vivo em ato. 3.ed. São Paulo: Hucitec, 2007b.

O ato de cuidar: a alma dos serviços de saúde. In: BRASIL. Ministério da Saúde. Secretaria de Gestão do Trabalho e da Educação na Saúde. Departamento de gestão da Educação na Saúde. VER - SUS Brasil: cadernos de textos. Brasília: Ministério da Saúde, 2004. p.108-37. (Série B - textos básicos de saúde). 
Em busca da qualidade dos serviços de saúde: os serviços de porta aberta para a saúde e o modelo tecnoassistencial em defesa da vida (ou como aproveitar os ruídos do cotidiano dos serviços de saúde e colegiadamente reorganizar o processo de trabalho na busca da qualidade das ações de saúde). In: CECíLIO, L.C.O. (Org.). Inventando a mudança em saúde. São Paulo: Hucitec, 1997. p.117-60.

MINAYO, M.C.S. O desafio do conhecimento: pesquisa qualitativa em saúde. 10.ed. São Paulo: Hucitec, 2007.

SANTOS, A.M. Da fragmentação à integralidade: construindo e (des)construindo a prática de saúde bucal no Programa de Saúde da Família (PSF) de Alagoinhas, BA. 2005. Dissertação (Mestrado em Saúde Coletiva) - Universidade Estadual de Feira de Santana, Feira de Santana. 2005.

SILVA JÚNIOR, A.G.; MASCARENHAS, M.M. Avaliação da atenção básica em saúde sob a ótica da integralidade: aspectos conceituais e metodológicos. In: PINHEIRO, R.; MATTOS, R. A. (Orgs.). Cuidado: as fronteiras da integralidade. Rio de Janeiro: Abrasco, 2004. p.241-57.

SILVEIRA FILHO, A.D. A saúde bucal no PSF: o desafio de mudar a prática. Bol. Prog. Saúde Fam., v.2, n.6, p.36-43, 2002.

SOUZA, E.R. et al. Construção dos instrumentos qualitativos e quantitativos. In: MINAYO, M.C.S.; ASSIS, S.G.; SOUZA, E.R. (Orgs.). Avaliação por triangulação de métodos. Rio de Janeiro: Fiocruz, 2005. p.133-56.

TEIXEIRA, R.R. Humanização e atenção primária à saúde. Cienc. Saude Colet., v.10, n.3, p.585-97, 2005.

O acolhimento num serviço entendido como uma rede de conversações. In: PINHEIRO, R.; MATTOS, R.A. (Orgs.). Construção da integralidade: cotidiano, saberes e práticas em saúde. Rio de Janeiro: Abrasco, 2003. p.89-111.

PINHEIRO, P.M.; OLIVEIRA, L.C. La contribución de la acogida y del vínculo de humanización de la práctica del cirujano dentista en el Programa Salud de la Familia. Interface - Comunic., Saude, Educ., v.15, n.36, p.187-98, jan./mar. 2011.

Se objetiva comprender como se emplean las tecnologías leves de la acogida y vínculo en la práctica del dentista, en el Programa Salud de la Familia del municipio de Fortaleza, del estado de Ceará, Brasil, en el sentido de la construcción del cuidado humanizado. Se trata de investigación cualitativa realizada con 16 cirujanos dentistas utilizando, para la colecta de datos, entrevista semi-estructurada y observación simple y, para análisis de los datos, un análisis de contenido. Los resultados muestran al dentista haciendo mayor uso de tales tecnologías en su práctica; la acogida, sin embargo, se identifica como primera etapa de organización de la demanda más que como actitud de escucha, una postura más asociada al vínculo. La gran demanda ha contribuido con líneas de tensión entre dentista y usuario, forzando al odontólogo a una práctica todavía sujeta al consultorio. Nuevos espacios serían importantes en la utilización de estas tecnologías ya que consideran, más allá de la enfermedad, al indivíduo.

Palabras clave: Acogida. Vínculo. Humanización. Cirujano dentista.

Recebido em 22/01/10. Aprovado em 21/07/10. 